\title{
Atingindo o infinito: combinatória e aleatoriedade na obra de Jesús Soto
}

Mariela Brazón Hernández ${ }^{1}$

\section{Resumo:}

Este artigo aborda duas questões centrais no estudo da obra do artista cinético latino-americano Jesús Soto (1923-2005): o uso de métodos combinatórios para gerar novos esquemas de estruturação da imagem, renunciando aos conceitos tradicionais de harmonia e composição, e a incorporação de elementos aleatórios na configuração das obras, com o intuito de multiplicar ad infinitum as possibilidades de performance das mesmas. A análise da produção do artista permitiu reconhecer a repetição, a permutação e a liberdade de ação como ideias fundamentais no processo de configuração formal e conceitual das obras. Assim, fruidor e obra artística agem como uma unidade cujo dinamismo é apenas uma parcela de um domínio físico mais extenso.

Palavras-chave. Arte latino-americana, arte cinética, arte e matemática, Jesús Soto.

Reaching the infinite: combinatorial procedures and randomness in Jesús Soto's work of art

\section{Abstract:}

\footnotetext{
${ }^{1}$ Bacharel em Computação e Bacharel em Artes pela Universidad Central de Venezuela. Mestre e doutora em Artes Visuais pela Universidade Federal do Rio de Janeiro. Professora do Instituto de Humanidades, Artes e Ciências (IHAC) e do Programa de Pós-Graduação em Museologia (PPGMuseu) da Universidade Federal da Bahia. E-mail: marielabrazon@yahoo.com.br
} 
This paper deals with two key issues in the study of the work of kinetic Latin-American artist Jesús Soto (1923-2005): the use of combinatorial methods to generate new schemes for structuring the image, renouncing to traditional concepts of harmony and composition, and the incorporation of random elements in the configuration of his works, with the purpose of multiplying ad infinitum the possibilities of their performance. The analysis of the artist production allowed us to recognize the repetition, the permutation and the freedom of action as fundamental ideas in the process of formal and conceptual configuration of his works. In this way, spectator and work of art act as a unit whose dynamism is only a portion of a much broader physical domain.

Keywords: Latin-American art, kinetic art, art and mathematics, Jesús Soto.

\section{A construção combinatória na produção de Jesús Soto}

Quando os artistas abstrato-geométricos decidem restringir seu vocabulário formal a um conjunto exíguo de elementos que se caracterizam por serem extremamente singelos, estão assumindo abertamente ou não, e mais consciente do que inconscientemente - um desafio criativo. Mestres pioneiros, como Mondrian e Malevich, reconheceram nessa frugalidade uma via idônea de aproximação ao ponto zero para onde deveriam convergir as propostas artísticas "verdadeiramente inovadoras" - isto é, segundo eles, aquelas capazes de mudar nossas maneiras de perceber e de reagir diante do percebido. Anos depois, os seguidores da abstração geométrica recorreram a essa mesma sobriedade formal como plataforma de decolagem das mais variadas experiências construtivas. Parece-nos apropriado falar de "desafio" porque na poética desses artistas está implícita a tarefa de gerar e diversificar partindo de um espectro limitado de possibilidades. Desta maneira, o ato artístico se aproxima, em mais de um aspecto, ao ato criador: aquele que se serve do simples para engendrar o complexo, que parte do escasso para dar nascimento 
ao profuso. Podemos apreciar melhor o alcance das limitações autoimpostas por esses artistas quando reparamos que as diretrizes por eles traçadas não se concentram apenas na simplificação do repertório formal; elas abrangem também os critérios e procedimentos a serem seguidos para gerar, organizar e apresentar a imagem. Recorrer a métodos combinatórios foi uma das opções adotadas pelos artistas cinéticos, dentre eles o venezuelano Jesús Soto, para sistematizar e controlar o ato criativo.

Entendemos por métodos combinatórios os procedimentos que permitem manipular um conjunto determinado de objetos, gerando novos conjuntos que cumprem condições específicas. Vejamos três exemplos de problemas combinatórios simples:

a. Dadas quatro figuras geométricas ( $\circ \mathbf{\Delta} \bullet$ ), desejamos explorar as diversas maneiras de distribuí-las sobre uma superfície quadriculada de modo que duas delas (digamos, o quadrado e o triângulo) nunca apareçam juntas.

b. A partir de seis pigmentos: $p_{1}, p_{2}, p_{3}$, das cores primárias, e $s_{1}, s_{2}, s_{3}$, das secundárias, queremos conhecer todas as maneiras possíveis de mesclá-los, de forma tal que em cada mescla intervenham apenas duas unidades de alguma cor primária e três de alguma secundária.

c. Dadas as seguintes notas musicais: Dó, Ré\#, Sol, Lá\#, Si, queremos achar os possíveis acordes de três notas que podem ser construídos a partir desse conjunto.

Saber se existem soluções e quantas, para problemas como os que acabamos de expor, determinar como podem ser geradas essas soluções e, inclusive, avaliá-las e selecionar dentre elas as mais convenientes para alcançar um objetivo ulterior, são algumas das tarefas abordadas pela Teoria Combinatória. Este ramo da matemática estuda certos problemas definidos sobre conjuntos discretos, como por exemplo: a enumeração de estruturas que satisfazem determinados requisitos (contagem combinatória), as maneiras de criar objetos de acordo com certos padrões (desenho combinatório) e a modelagem de algumas situações nas quais estão involucradas variáveis discretas (teoria de grafos). 
A Teoria Combinatória apoia-se em conceitos básicos aplicáveis a um conjunto finito de elementos. Se o conjunto em questão é $A=\left\{a_{1}, a_{2}, a_{3}, \ldots a_{m}\right\}$ - onde $m$ é a cardinalidade de $A-$, podemos escolher $n$ elementos desse conjunto $(n \leq m)$, e com eles formar arranjos $\left(r_{1}, r_{2}, r_{3}, \ldots, r_{n}\right)$. A maneira de configurar as escolhas dependerá de critérios como: repetição ou não dos elementos, diferenciação entre os mesmos, circularidade etc. A Teoria Combinatória mostra como com ferramentas muito simples podem ser criadas novas entidades compostas, multiplicando assim as possibilidades oferecidas pelos elementos de base. Não importa se estes são poucos. A relação entre o número de elementos em jogo e o total de arranjos possíveis é, na maioria dos casos, exorbitante, especialmente se o procedimento escolhido for o da permutação, no qual o coeficiente gerador é da ordem fatorial: a partir de quatro elementos podem ser gerados 24 arranjos; já com seis elementos (um incremento de apenas dois), o total de arranjos pula abruptamente para 720; e apenas com dez, a quantidade de arranjos atinge a impressionante cifra de 3.628.800. A Teoria Combinatória ajuda a construir situações tão numerosas e variadas que frequentemente acaba resultando difícil a apreensão das mesmas como totalidades, motivo pelo qual a realidade gerada combinatorialmente pode parecer-nos tão próxima daquilo que imaginamos ser o infinito. $^{2}$

Com o intuito de atingir imagens mais "objetivas", os artistas que recorrem a métodos combinatórios renunciam ao controle em pelo menos dois momentos em que poderiam manifestar-se os impulsos pessoais (i.e. subjetivos): 1) na escolha dos elementos com os quais se construirá a imagem; 2) na aceitação ou negação de uma relação de ordem entre eles - para alguns artistas, uma certa ordem entre os elementos induz uma indesejada escala hierárquica e de valor. Procedendo

\footnotetext{
2 Janet Zweig (1997) cita o exemplo do Sefer Yetzirah, texto místico que explica como o Universo foi criado ao serem permutadas as 22 letras do alfabeto hebreu. Em total, as 1.124.000.727.777.607.680.000 combinações possíveis são tantas, que nenhuma boca poderá pronunciá-las nem nenhum ouvido poderá ouvi-las.
} 
Atingindo o infinito: combinatória e aleatoriedade ...

combinatorialmente nesses dois momentos, o artista tenta minimizar, tanto quanto possível, a influência do gosto pessoal, distanciando-se também da busca tradicional de harmonia e equilíbrio. Seu papel limita-se, então, a materializar (total ou parcialmente) o que a distribuição combinatória predeterminou.

Em alguns casos, a própria opção combinatória se converte em uma espécie de marca pessoal, pois para alguns artistas, ela é, mais do que uma ferramenta, um fim em si mesmo, e a obra plástica é a via para expor, por meios sensíveis, o conjunto de situações geradas combinatorialmente - lembremos, por exemplo, de certas obras de Sol LeWitt onde o que é relevante não é a imagem criada por via combinatória, mas a ideia mesma de combinar exaustivamente.

Os métodos combinatórios, com seu poder multiplicativo, foram verdadeiramente úteis para os artistas da linha construtivista porque, além de incrementar as potencialidades de uma matériaprima abreviada intencionalmente, introduzem entre os elementos plásticos ordenamentos que não dependem de fatores subjetivos, anulando (quando menos teoricamente) as hierarquias de formas, cores e localizações espaciais tradicionalmente adotadas nas artes visuais. Sob um esquema combinatório, os elementos aparecem em cena, ora aqui ora lá, sem maior ou menor relevância. A distribuição (no plano ou no espaço) de acordo com uma ordem prefigurada combinatorialmente contribui para que os estímulos no campo visual mantenham certa homogeneidade, sem por isso cair na monotonia.

A ativação livre da superfície pictórica, resultante da organização da imagem por meios combinatórios, é um dos pontos que mais atrai os artistas que seguem a linha cinética - tanto os que se interessam estritamente pelos fenômenos ópticos, como aqueles que incorporam efeitos mecânicos que vão além do puramente visual. Para a maioria desses artistas, recorrer a métodos e conceitos combinatórios significa, basicamente, introduzir na obra modificações controladas por parâmetros extraartísticos. A mera ideia de combinar já lhes parece um excelente 
ponto de partida para definir novos esquemas estruturais, nos quais a multiplicidade, construída a partir da simplicidade, favorece a aparição de imagens em movimento. Seja por vias estritamente racionais ou por caminhos intuitivos, o artista que trabalha baseado nos procedimentos combinatórios deixa em evidência a enorme potencialidade do seu alfabeto plástico-formal, transladando o fruidor a um mundo de infinitas possibilidades que, longe de ser inviável, é perfeitamente factível e parece estar realmente ao seu alcance.

Conceitos combinatoriais básicos foram explorados por Jesús Soto de pelo menos dois ângulos diferentes: a) para selecionar e ordenar elementos plástico-formais sem depender de fatores subjetivos; b) ao trabalhar com imagens cinéticas nas quais fosse preponderante a sensação de alternância. Vejamos com mais detalhe cada uma dessas abordagens:

Muro blanco (1952-53) - Figura 1 - é uma das obras em que Soto utiliza mais claramente o procedimento da Permutação como ferramenta de seleção e ordenação. A obra é formada por 24 painéis brancos colocados em um arranjo de quatro filas e seis colunas. Cada um dos quadrados possui dois setores separados por uma fileira de pontos pretos: do lado direito um setor liso e do lado esquerdo um setor ocupado por fileiras verticais de pontos brancos. Imaginemos que em cada posição de uma matriz de quatro filas e seis colunas colocamos o número que corresponde ao total de fileiras verticais de pontos brancos de cada painel. Obteremos, então, os seguintes valores:

$$
\left(\begin{array}{llllll}
7 & 5 & 6 & 5 & 6 & 7 \\
4 & 6 & 5 & 6 & 5 & 4 \\
6 & 4 & 7 & 4 & 7 & 5 \\
5 & 7 & 4 & 7 & 4 & 6
\end{array}\right)
$$


...o que mostra que cada coluna é uma permutação dos elementos do conjunto $\{4,5,6,7\}$; onde sempre aparecem juntos os dígitos "7" e "4", e "6" e "5". Estas relações nos levam a pensar que a distribuição dos pontos foi determinada pelo artista tomando como base um arranjo numérico pré-escolhido. Mais ainda, o fato de não estarem presentes todas as permutações dos quatro elementos $\{4$, $5,6,7\}$ - que são 24 no total - e, inclusive, a repetição de uma em particular (observe-se que as colunas 2 e 4 são idênticas), indica que o artista fez escolhas a partir do amplo espectro de possibilidades oferecido pelos procedimentos combinatórios.

Nesta obra, a configuração dos pontos de cada painel é potencializada pela inclinação de cada peça, criando assim um efeito dinâmico. Em Muro blanco, cada quadrado é um bloco com sua superfície inclinada por um dos lados. Se em uma matriz registramos o lado pelo qual cada bloco se levanta, obteremos os seguintes valores:

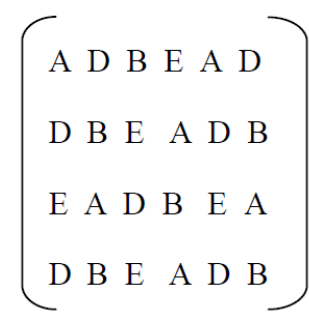

" $A$ " significa que o lado mais alto desse bloco é o de cima, " $B$ " o de baixo, "D" o da direita e "E" o da esquerda.

Lendo estes valores horizontalmente - isto é, por filas, de esquerda à direita - observaremos que as inclinações dos painéis seguem o sentido de rotação dos ponteiros de um relógio (...E, $A, D, B, E, A, D$, $B, E, A, \ldots)$. Estamos, portanto, perante um movimento que responde a um projeto e que, ainda aparentando ser livre, é, na verdade, o produto de relações predefinidas e de recortes feitos $a$ priori pelo artista.

Em Muro blanco, como em outras obras, Soto seleciona um fragmento de uma realidade que poderia estender-se 
indefinidamente; fragmento que contém informação suficiente para deduzirmos o princípio estrutural que rege a totalidade. A repetição serve para acentuar o caráter reiterativo de um esquema que pode aplicar-se ad infinitum. Soto, como outros artistas, enfrenta o problema de apresentar o infinito servindo-se de meios sensíveis finitos. Para tanto, sugere, mediante a repetição, que a realidade retratada pode continuar além dos limites da obra e, inclusive, além de todo limite imposto pela imaginação. Assim, os recursos combinatórios são o apoio extra-artístico que lhe serve para selecionar os elementos que hão de entrar em cena e a ordem em que o farão; a imaginação do fruidor ocupar-se-á do resto: extrapolando o que vê e transbordando os limites físicos da obra.

A noção de permutação é usada por Soto para se referir também à simples ideia de alternância, tanto espacial quanto temporal. Daí que ele tenha empregado o vocábulo "permutação" para titular obras nas quais certos elementos vibram e intercambiam (aparentemente) suas posições em um movimento incessante de vaivém - caso de Permutation (1956) - Figura 2 - e Permutación (1965) - Figura 3. Na primeira dessas obras, a divisão do fundo listrado em dois setores ligeiramente defasados provoca fragmentação nas linhas brancas desenhadas sobre o plexiglas, as quais parecem deslocar-se alternadamente para a direita e para a esquerda. O fundo, por sua vez, vê-se contagiado por esse movimento aparente. Na segunda obra, as linhas são fragmentadas e não o fundo, por isso, cada um dos segmentos, branco e preto, se "movimenta" sempre na direção oposta à de seu vizinho, como se ocupasse a posição que acaba de ser liberada. $O$ estudo desse tipo particular de movimento, em que dois ou mais objetos parecem permutar entre si, foi pesquisado por Soto, introduzindo ligeiras variações formais. Em todos os casos, o que ele explora, em essência, é a dinamização do plano pictórico a partir de uma fonte mínima de recursos, o que justifica também a preferência pelo par de valores branco/preto. 


\section{$O$ aleatório, 0 inesperado}

Podemos dizer que, para muitos artistas, a atitude combinatória funciona com efetividade quando se trata de controlar determinadas fases do processo criativo. Entretanto, em outros sentidos, esse recurso apresenta limitações. A primeira delas é que os resultados obtidos por via combinatória, embora sejam numerosos, não deixam de ser finitos - e um bom número de artistas cinéticos deseja trabalhar/transmitir uma "realidade infinita". A segunda é que sempre que os resultados combinatórios são apresentados (extensa ou abreviadamente, de maneira organizada ou não), eles trazem consigo evidências de terem sido gerados de acordo com uma programação racional, predeterminada, que dá pouca cabida ao inesperado (um efeito pelo qual vários artistas cinéticos sentem inclinação).

A abordagem combinatória apresenta-se, em princípio, como uma fonte de infinitas possibilidades - como acontece com a retícula. Fonte que, no entanto, sempre corre o risco de esgotar-se por extenuação, além de mostrar-se racional em demasia, quando cotejada com a liberdade que promete. A maioria dos artistas abstrato-geométricos, construtivos e cinéticos defende, em maior ou menor grau, a não-subjetivização do processo de criação plástica, fazendo o possível para que o distanciamento entre a obra e os impulsos pessoais fique evidente na imagem. Alguns percebem, entretanto, que delegar o controle exclusivamente a formulações matemáticas, distribuições regulares predefinidas e métodos de seleção e ordenamento sistemáticos (como os métodos combinatórios), empobrece o resultado. É por isso que a atenção desses artistas se dirige a outra fonte de recursos, também externa em relação a seu mundo pessoal, e muito mais prolífica no que diz respeito a sua potencialidade geradora. Referimo-nos à aleatoriedade, com sua capacidade de instaurar uma ordem não previsível e inibir a manifestação do livre arbítrio do autor. 0 próprio Soto nos fala de como se deu nele essa abertura ao universo dos fenômenos aleatórios, suas leis e indeterminações: 
No início fazia coisas estruturadas empregando elementos geométricos. Em seguida, tentei fazer evoluir essa geometria em direção a uma escrita mais livre. [...] Antes realizava o quadro como uma coisa previsível, preconcebida. No entanto, mais tarde, vim valorizar, na realização das minhas obras, elementos de encontro e de acaso. [...] Para mim, o acaso é o elemento vivo que me causa um tipo de surpresa. (Soto apud Pierre, 1998)

Especialmente para os artistas cinéticos - interessados na essência do movimento e da mudança -, fez-se necessário abandonar a simplicidade de um mundo regular e previsível, para assumir os riscos de transitar pelo terreno do flutuante, o fortuito, o espontâneo e, consequentemente, o reticente a planejamento. Alguns artistas dessa linha delegaram o controle a mecanismos (motorizados ou não) que permitiam efetuar ações específicas, deixando espaço para movimentos aleatórios - exs. David Medalla e suas Bubble Machines; Jean Tinguely e suas obras mecanizadas. Outros introduziram diversos graus de liberdade na própria estrutura da obra, permitindo a manipulação pelo espectador, a realização de movimentos inesperados e/ou a quebra da regularidade - ex. obras transformáveis/manipuláveis de Yaacov Agam. (Popper, 1968)

Na obra de Soto, como na de outros artistas que recorreram à aleatoriedade, está presente a marca de Hans Arp e de seus collages concebidos segundo as leis do acaso (according to the laws of chance), onde o fenômeno imprevisível de objetos caindo livremente sobre uma folha de papel Ihe serviu para anular todo resquício compositivo. Vejamos o relato do próprio Arp citado por Döhl ([19--], tradução nossa):

Trabalhando juntos [com Sophie Taeuber], ou sozinho, bordamos, tecemos, pintamos, colamos figuras geométricas e estáticas. Estruturas impessoais e austeras foram criadas a partir de planos e cores. Nenhuma mancha, rasgadura, fibra ou inexatidão danificava a clareza do nosso trabalho. Inclusive, descartamos as tesouras com as que havíamos inicialmente 
Atingindo o infinito: combinatória e aleatoriedade ...

cortado as imagens de papel, pois elas revelavam muito claramente o envolvimento pessoal da mão. Depois disso usamos uma máquina corta-papéis. [...] Eu continuei desenvolvendo trabalhos colados, estruturando-os espontaneamente, automaticamente. Chamei a este trabalho "de acordo com a lei do acaso". A "lei do acaso", que incorpora todas as leis e é tão inescrutável para nós como o é o abismo de onde vem a vida...

Soto conhece o trabalho de Arp tão logo chega a Paris (1950), e manifesta, desde cedo, seu apreço pela obra do mestre alsaciano. (Pierre, 1998) Não sabemos, ao certo, se esse foi o primeiro contato do jovem venezuelano com o uso de recursos aleatórios como ferramentas construtivas, mas podemos afirmar que na obra de Soto, como na de Arp, a introdução de fatores aleatórios responde a uma compreensão profunda da Natureza e de seus processos essenciais: movimento e transformação para Soto, e crescimento e plasticidade orgânica para Arp.

Amanhã, como ontem, - explica Soto - minha arte continuará ligada ao aleatório e tem que evitar, em todo momento, aproximar-se do dado definitivo, pois não é sua preocupação definir nem representar a realidade de um certo e determinado instante, mas, pelo contrário, revelar a infinitude e a temporalidade como valores universais. $O$ universo é para mim aleatório. Minha obra também deve sê-lo. (Soto citado por Joray, 1984 , p. 140, tradução nossa)

A maneira como Soto recorre ao aleatório está fortemente relacionada com seu desejo de estabelecer interações entre a obra de arte e o entorno. Especificamente em suas obras cinéticas, a aleatoriedade se faz presente mediante duas intervenções externas imprevisíveis: a do espectador e a dos fenômenos ambientais que movimentam os elementos livres de cada obra. Em ambos os casos, a noção de aleatório com que Soto trabalha se confunde com a de indeterminado - isto é, tudo aquilo que se encontra fora do controle do artista, mas que, estritamente falando, não se 
manifesta de maneira completamente casual. Um exemplo de evento indeterminado (mas não aleatório), explica Janet Zweig (1997), é a maneira como diferentes intérpretes executam uma mesma peça musical. Apoiando-nos nessa explicação, e levando em consideração as características das obras de Soto, podemos ver em cada fruidor uma espécie de "executante", cujos movimentos corporais desencadeiam uma infinidade de imagens e sensações. Essa energia vibratória, que parecia encontrar-se em estado latente, é liberada com plenitude e espontaneidade, de maneira livre e indeterminada, sem intervenção ou orientações do artista Figura 4. Assim, a obra cinética se constitui como um verdadeiro campo de liberdades.

Poderíamos perguntar-nos se as manifestações espontâneas do espectador não ameaçam a dessubjetivização ambicionada pelo artista e tão atentamente trabalhada durante as etapas de criação. Será que estamos perante uma arte na qual uma boa parcela de subjetividade manifesta-se agora na etapa de fruição? A pergunta seria pertinente se não levássemos em conta que, quando menos inicialmente, o que impulsiona o espectador para confrontar a obra de Soto, de um ou doutro ângulo ou com uma determinada cadência, não são estritamente fatores que emanam de seu universo emocional, mas, principalmente, a conscientização de estar fazendo parte da obra e de poder, como fruidor, controlar certas variáveis da sua performance.

O espectador ativa essas estruturas à medida de sua própria atividade, se ele, por si próprio, começar a ser ativo, num jogo livre e sem nenhuma conformidade perceptível com as leis. [...] O movimento das imagens é o movimento do espectador, o qual no jogo mútuo da estrutura e do movimento do corpo tornase consciente de seu próprio movimento. Ao mesmo tempo, torna-se consciente do fato de que as estruturas em repouso, como todas as coisas em repouso, não significam nada nelas mesmas. (Wenberger citado por Pierre, 1998, não paginado) 
A simbiose entre espectador e obra pode desembocar muito facilmente no terreno do lúdico, onde - ali sim - florescerão com mais liberdade os impulsos do nosso insondável mundo interior.

Além da intervenção do espectador, mencionávamos os fatores ambientais. Em particular o vento, que, também de forma indeterminada, afeta a posição das peças pendentes, trazendo, nesse balanço, referências à instabilidade, à fluidez e à fragilidade de certos elementos da Natureza. Nas obras de Soto que possuem elementos livres oscilantes, os materiais usados oferecem o grau de liberdade necessário para que infinitas microvibrações se manifestem em toda a superfície da obra. São efeitos visuais inesperados e sempre variantes, de uma riqueza que impressiona pelas numerosas possibilidades.

Sentimo-nos maravilhados diante das leis do acaso, sem perceber que o que acontece é que tomamos consciência de realidades com as quais não tínhamos "sonhado". Os elementos submergem-se na obra como o peixe na água; todos seus acidentes, direções, velocidades, posições, estão ordenados por um todo que os envolve, do qual são tributários e que, por sua vez, condiciona suas variantes. A força desses elementos pode ser medida pelo número de suas revelações. Este estado, consciente ou não, do artista contemporâneo, deu à arte do nosso tempo essa surpreendente riqueza de possibilidades. (Soto citado por Joray, 1984, p. 172, tradução nossa)

Em suas obras, Soto não quer esgotar as possibilidades nem limitar/direcionar as vias de aproximação. Pelo contrário, prefere deixar aberturas, passagens livres, para que a imagem possa ser acolhida "universalmente". Porém, essas aberturas são racionalizadas, de maneira a evitar leituras excessivamente pessoais por parte do fruidor. É o caso dos Penetráveis, sempre confeccionados em estrito formato cúbico, para que nossa imaginação não Ihes atribua nenhum tipo de interpretação figurativa - "[Dar ao penetrável a forma de cubo] é o mais evidente, 
do contrário, o público o percebe como algo desenhista, dando a qualquer outra forma um valor estético que não tem para mim [...]" (Soto citado por Jiménez, 2001, p. 71, tradução nossa). Assim, a obra oscila entre o pessoal, que aflora naturalmente na fruição, e as limitações impostas pelo artista para que essa subjetividade não transborde.

A Combinatória e a Aleatoriedade oferecem, junto com a base formal geométrica, a possibilidade de abrir suficientemente a obra (diversificando a imagem, enriquecendo suas possibilidades) sem por isso perder o controle e penetrar no complexo mundo do subjetivo. Há na geometria calculada de Soto um grau de liberdade que só existe na Natureza. Não como forma, mas como processo. $\mathrm{O}$ que nela há de imprevisível é o verdadeiro motor do cinetismo proposto pelo artista. A confluência da Combinatória com a Aleatoriedade aproxima-nos do domínio do ilimitado, o infinito, o incontável, o inesperado. Além de ferramentas para gerar a matéria prima a ser trabalhada, elas são, em si mesmas, matéria prima para as reflexões do nosso artista sobre o mundo físico que nos rodeia e do qual fazemos parte ativa.

\section{Referências}

Centro Cultural Banco do Brasil. (2005). Soto: A construção da imaterialidade (Catálogo de exposição). Rio de Janeiro: CCBB.

Döhl, R. ([19--]). Hans Arp and Zurich Dada. Stuttgart: Universität Sttugart.

Jiménez, A. (2001). Conversaciones con Jesús Soto. Caracas: Fundación Cisneros. (Colección Patricia Cisneros, Cuaderno 6). Joray, M. (1984). Soto. Nêuchatel: Griffon. 
Atingindo o infinito: combinatória e aleatoriedade ...

Pierre, A. (1998). Cronologia. In: Soto (Catálogo de exposição). Paris: Jeu de Paume.

Popper, F. (1968). Origins and development of kinetic art. London: Studio Vista.

Zweig, J. (1997). Ars combinatoria: mystical systems, procedural art, and the computer. Art Journal, New York, 56 (31). 
Mariela Brazón Hernández

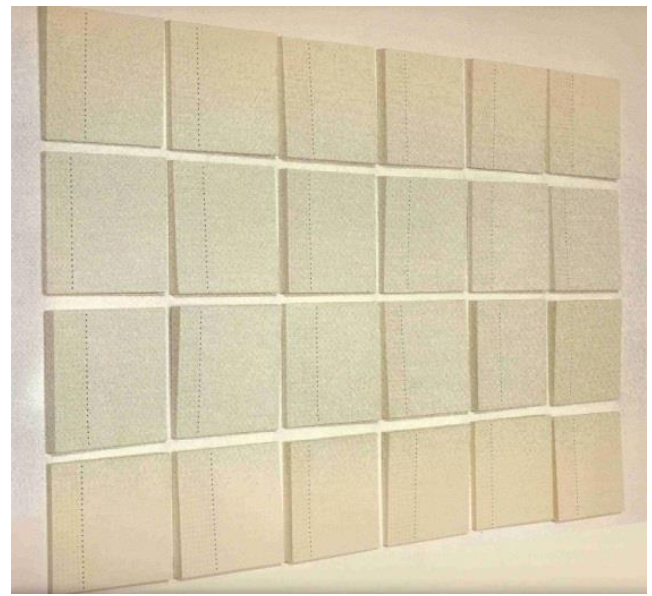

Figura 1

Muro blanco, 1952-53, $215 \times 325 \times 5,5 \mathrm{~cm}$.

Fonte: Joray (1984, p. 42).

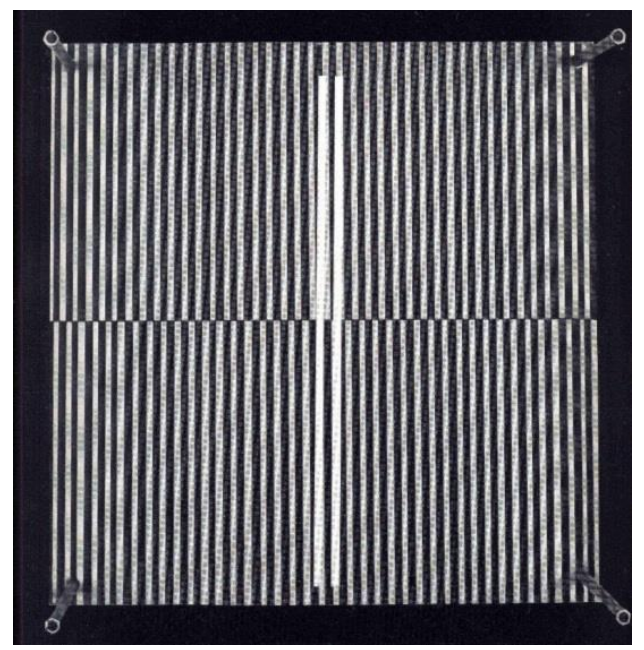

Figura 2

Permutation, 1956, $40 \times 40 \mathrm{~cm}$.

Fonte: Joray (1984, p. 58). 
Atingindo o infinito: combinatória e aleatoriedade ...

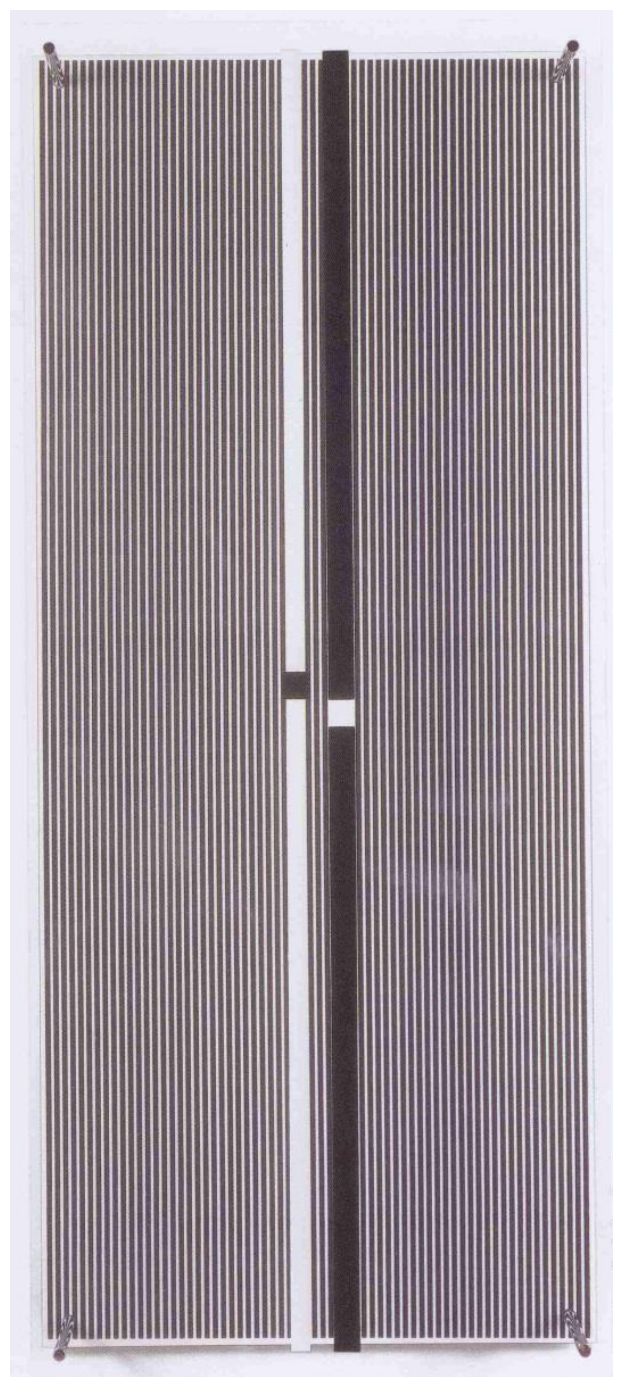

Figura 3

Permutación, 1965, 70 × $30 \mathrm{~cm}$.

Fonte: Centro Cultural Banco do Brasil (2005, p. 65). 
Mariela Brazón Hernández

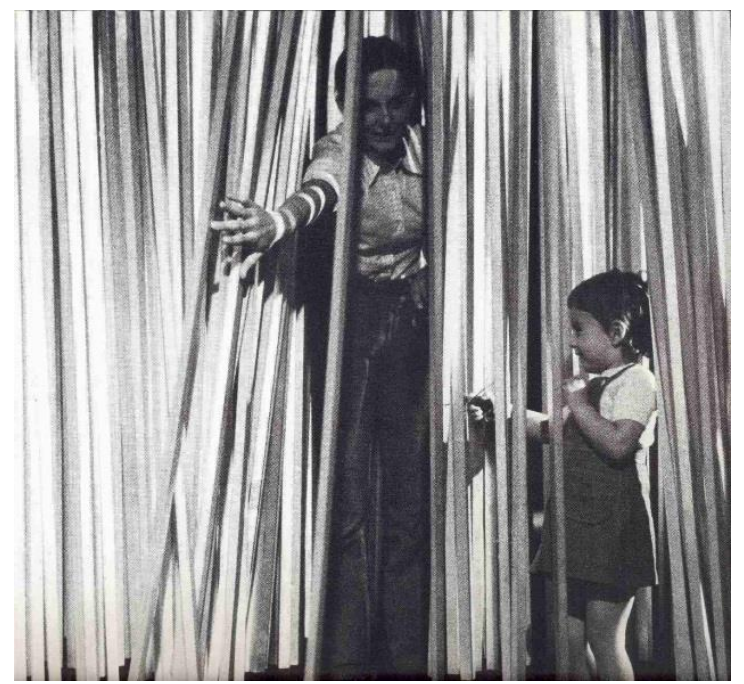

Figura 4

Penetrable sonoro, 1970, $248 \times 225 \times 410 \mathrm{~cm}$.

Fonte: Joray (1984, p. 180). 